complaints about the cost of the commercial slides having to be borne by the general practice. For this reason, and because of the inconvenience of collecting urine specimens, their use has been small. Greater use would allow prompt and effective treatment for many ill children whose urine infection has not been identified. It also would prevent unnecessary treatment of the many children who have urinary tract symptoms but no infection.

${ }^{1}$ Kunin, C, Zacha, E, and Paquin, A J, New England fournal of Medicine, 1962, 266, 1287.

2 Meadow, S R, White, R H R, and Johnston, N M, British Medicalfournal, $1969,3,81$.

3 Savage, D C L, et al, British Medical fournal, 1969, 3, 75.

\section{The Budd-Chiari syndrome}

Obstruction to the venous outflow from the liver is rare, but it produces a dramatic and often fatal illness. This was first described by Budd in 1845, when he was professor of medicine in London. ${ }^{1}$ The other half of the eponym came from a review of 13 cases by Chiari in $1899 .^{2}$ The syndrome is produced by occlusion of the major hepatic veins or the vena cava at that level; it should be distinguished from so-called veno-occlusive disease of the liver, usually seen in children, in which there is progressive obliteration of small intrahepatic veins.

The obstruction in the Budd-Chiari syndrome is caused by thrombus in the major hepatic veins or their ostia, and in cases running a chronic course thrombus may become organised into fibrous tissue. A variant described mainly from Japan is obstruction of the vena cava at the level of the hepatic venous ostia by a fibrous membrane or web $^{3}$ - presumably congenital, though the delay in clinical presentation is surprising.

The cause remains problematical. In a review of 164 cases Parker could find underlying causes in only $30 \%{ }^{4}$ These included polycythaemia rubra vera, leukaemias, trauma, hydatid disease, and invasion of hepatic veins by primary and secondary liver tumours. Paroxysmal nocturnal haemoglobinuria and, more recently, oestrogen-containing oral contraceptive pills should now be $\operatorname{added}^{56}$ to this list. Men and women are equally affected, and most patients are in their $20 \mathrm{~s}$ or $30 \mathrm{~s}$. The clinical picture is dominated by ascites, enlargement of the liver, and abdominal pain. In about a fifth of patients the illness is fulminant with a rapid downhill course leading to death in liver failure within a few weeks. More commonly symptoms have been present for two to six months by the time the patient is first seen, and this more insidious onset may reflect either gradual occlusion of the hepatic venous outflow or a more efficient collateral circulation.

Clinical diagnosis is often difficult and demands a high index of suspicion. The most common differential diagnosis is cirrhosis with portal hypertension, but congestive cardiac failure and constrictive pericarditis need to be considered. The results of biochemical tests of liver function are usually abnormal, and about one-third of patients are jaundiced. ${ }^{4}$ Percutaneous needle biopsy specimens of the liver will show hepatic venous congestion with areas of centrilobular necrosis and haemorrhage. To distinguish the Budd-Chiari syndrome from other causes of venous congestion of the liver ${ }^{7}$ - important if surgery is planned-the inferior vena cava and hepatic veins need to be delineated. Swelling of the liver produces characteristic narrowing of the cava just below the diaphragm. ${ }^{7}$
At least one major hepatic vein can usually be catheterised at venography, when injection of contrast medium in the wedged position will show a typical spider web network of small venous collaterals. When an experienced operator fails to cannulate the hepatic vein and there is no reflux of contrast into the hepatic veins during a Valsalva manoeuvre the balance of probability is strongly in favour of occlusion of the hepatic vein.

Radioisotope scintiscanning may show a central "hot spot" as a result of sparing of the venous drainage of the caudate lobe through small branches separate from the main right and left hepatic veins. ${ }^{8}$ Nevertheless, the findings from the liver scan are not always diagnostic, and there may be patchy liver uptake combined with large extrahepatic uptake in the spleen and bone marrow, an appearance indistinguishable from cirrhosis. ${ }^{9} 10$

Patients who present with a fulminant illness die rapidly in hepatic coma. Those with a more gradual course may be improved temporarily by general medical measures, but many later succumb to bleeding from oesophageal varices. ${ }^{11}$ The overall two-year survival is less than $10 \%$. Diuretics and salt restriction are the cornerstones of medical management, combined with treatment of any underlying cause such as polycythaemia rubra vera. Anticoagulants and fibrinolytic agents have been used, ${ }^{12}$ but the results have been disappointing.

Various aggressive approaches have been tried in an attempt to prevent the development of portal hypertension and deterioration in liver function. Membranous obstruction to the inferior vena cava may be corrected by transatrial membranotomy. ${ }^{1314}$ Portal decompression by shunt surgery is an attractive concept, but the results have been mostly disappointing-that is, until a recent report from Orloff and Johansen. ${ }^{10}$ Using side-to-side portacaval shunts, they achieved complete resolution of ascites, disappearance of hepatosplenomegaly, and biochemical recovery in five of six patients, who have now been followed for between eight months and seven years. Preoperative hepatic venography and splenic arteriography with late films are essential to confirm patency of the vena cava and the portal vein. In patients in whom the inferior vena cava is occluded mesoatrial grafts ${ }^{10}$ and orthotopic transplantation ${ }^{15}$ have been tried with occasional success. The LeVeen peritoneojugular shunt may produce dramatic resolution of ascites, ${ }^{16}$ but as it does not decompress the congested liver there is no reason to expect improvement in hepatic function or portal hypertension; it should be reserved for patients in whom more definitive surgery is not feasible. Thus we await really effective treatment for patients with this syndrome.

1 Budd, G, On Disease of the Liver, p 147. London, Churchill, 1845.

${ }^{2}$ Chiari, H, Beiträge zur Pathologischen Anatomie und zur Allgemeinen Pathologie, 1899, 26, 1.

3 Takeuchi, J, et al, American fournal of Medicine, 1971, 51, 11.

4 Parker, R G F, Medicine (Baltimore), 1959, 38, 369.

5 Sterup, K, and Mosbech, J, British Medical fournal, 1967, 4, 660.

- Wu, S-M, Spurny, O M, and Klotz, A P, American fournal of Digestive Diseases, 1977, 22, 623.

${ }^{7}$ Kreel, L, Freston, J W, and Clain, D, British Fournal of Radiology, 1967, 40, 755 .

8 Tavill, A S, et al, Gastroenterology, 1975, 68, 509.

${ }^{9}$ Chaudhuri, T K, et al, fournal of the American Medical Association, 1972, 221, 506.

10 Orloff, M J, and Johansen, K H, Annals of Surgery, 1978, 188, 494.

1 Schramek, A, et al, Annals of Surgery, 1974, 180, 368.

12 Warren, R L, et al, Gastroenterology, 1972, 62, 200.

${ }^{13}$ Kimura, C, et al, fournal of Cardiovascular Surgery, 1962, 3, 393.

14 Kimura, C, et al, Surgery, 1972, 72, 551.

15 Putnam, C W, et al, fournal of the American Medical Association, 1976, 236, 1142.

16 LeVeen, H H, et al, Annals of Surgery, 1976, 184, 574. 